\title{
Vistas de ciudades andaluzas hasta mediados del siglo XIX
}

Antonio Gámiz Gordo, Escuela Técnica Superior de Arquitectura de Sevilla

Desde el presente artículo se reivindica la importancia de estudiar las vistas de ciudades realizadas a lo largo de la historia como valiosa fuente para conocer mejor las transformaciones de sus territorios, paisajes y arquitecturas. Éstas tienen un singular valor si son previas a la aparición de la fotografía como registro documental a mediados del siglo XIX. La elaboración de vistas ha compartido intereses con la producción cartográfica sobre la ciudad, aunque no se basan en el sistema diédrico o acotado -como ocurre en mapas, planos o perfiles-, sino en la perspectiva. Resultan fáciles de comprender y suelen usar lenguajes gráficos subjetivos o personales, que deben interpretarse caso a caso, atendiendo a los intereses de cada autor, a su contexto y recursos gráficos o habilidades, considerando siempre la propia realidad dibujada.

Desde dichas premisas este artículo aporta una visión general del numeroso y heterogéneo conjunto de vistas históricas de ciudades andaluzas hasta mediados del siglo XIX. No pretende cerrarse un listado ni una valoración detallada, sino destacar ciertas colecciones, series o piezas singulares, configurando una idea global aproximada sobre un precioso conjunto documental cuyo conocimiento debe progresar en un futuro próximo. Las vistas se presentan por orden cronológico. Tras las imágenes más primitivas se destacan dos excepcionales colecciones de finales del XVI. Después se reseñan vistas del XVII y XVIII, muchas elaboradas sobre plantas, y por último se citan exquisitas colecciones de vistas paisajísticas deI XIX, hasta la aparición de la fotografía. Además se aporta una bibliografía básica con una selección de más de 40 obras sobre el asunto planteado.

\section{Palabras clave}

Andalucia / Cartografías / Ciudades históricas / Dibujantes / Grabadores / Grabados / Historia / Patrimonio cultural / Patrimonio documental / Vistas de ciudades / 1360-S XIX
Las vistas y perspectivas de ciudades realizadas a lo largo de la historia constituyen un patrimonio gráfico del mayor interés para conocer mejor la evolución o transformaciones de su contexto territorial, sus paisajes, perfiles y arquitecturas.

En muchos casos la elaboración de vistas urbanas ha compartido objetivos o intereses con la producción cartográfica sobre la ciudad, pero con una obvia e importante diferencia en su construcción gráfica: la cartografia urbana suele usar el sistema diédrico o acotado para producir mapas, planos o perfiles, mientras que las vistas suelen apoyarse en la perspectiva. Así, los planos de ciudades normalmente responden a ciertas codificaciones o convenciones geométricas, o sea, a un lenguaje gráfico bastante objetivo, aunque su comprensión no siempre resulta fácil a personas no especializadas en el tema. Por el contrario las vistas urbanas son más fáciles de comprender, pues evocan directamente la realidad visual, aunque suelen basarse en codificaciones más diversas que a menudo se apartan de las estrictas reglas geométricas de la perspectiva. 0 sea, las vistas usan lenguajes gráficos más subjetivos o personales, cuya interpretación rigurosa requiere un análisis especializado en cada caso.

Para plasmar sus vistas cada dibujante emplea recursos gráficos propios, ligados a su trayectoria personal o artística, con variados formatos y técnicas de línea o mancha (lápiz, tinta, acuarela...), y a veces con sofisticados artilugios gráficos, como por ejemplo la cámara oscura, antecedente histórico de la fotografía. Debe atenderse a dichos procesos gráficos en cada autor y en cada imagen, considerando que muchas vistas del natural fueron rehechas o manipuladas por grabadores o litógrafos para publicaciones que a veces tuvieron una gran difusión o repercusión cultural fuera de nuestras fronteras.

Por tanto, para valorar el interés documental -y también estéticode las vistas urbanas, se considera necesario abordar su análisis caso a caso. Para ello, cada vista puede compararse con imágenes actuales tomadas desde lugares próximos o con vistas de otros tiempos, si resulta posible. Debemos aproximarnos a los intereses de cada autor, a su contexto histórico o cultural y a los recursos usados en cada construcción gráfica, evitando siempre generalizaciones reduccionistas. La investigación sobre cada vista puede 
ofrecer variados argumentos según el enfoque del análisis planteado o los episodios elegidos: topografía y perfiles, caminos y cultivos, murallas y puertas, calles y plazas, personajes y costumbres, arbolado y jardines, arquitecturas singulares...

Todo ello deberia tener una evidente repercusión en el mejor y necesario conocimiento paisajístico de nuestras ciudades. Sin embargo, las vistas urbanas parecen algo olvidadas por el urbanismo actual y por las instituciones públicas. En muchos atlas o libros sobre historia urbana las vistas se reducen a meras curiosidades o adornos. Y la planificación de ciudades en la actualidad se basa mucho en planos de planta, pero poco en vistas que reflejen lo percibido por el ojo humano, generándose paisajes indeseados o indefensos por todos conocidos, aunque esta cuestión no será la que aqui se aborde.

Desde dichas consideraciones previas, este artículo intenta aportar, como material básico para estudios más amplios, una visión general sobre el numeroso y heterogéneo conjunto de vistas históricas de las ciudades andaluzas. No se pretende cerrar un listado ni una valoración definitiva o detallada de las mismas, pues muchas están aún pendientes de clasificación y estudio. Sencillamente trata de destacarse el valor de ciertas colecciones, series o piezas, apuntando datos para configurar una idea global aproximada sobre un precioso conjunto documental cuyo conocimiento debe progresar en un futuro próximo'.

Para ello se organiza un breve recorrido temporal, iniciado con las primeras imágenes conocidas hacia el siglo XIV, abarcando - por motivos de extensión- sólo hasta mediados del XIX, cuando apareció la fotografia, heredera de la vieja tradición vedutista. La llegada de estas nuevas imágenes, objetivas y fiables, supuso una gran revolución en las formas de ver y comprender nuestras ciudades hasta ese momento, similar a la que ha tenido lugar en nuestros dias con la llegada de la informática y la imagen digital.

\section{PRIMERAS Y PRIMITIVAS VISTAS URBANAS}

Las primeras vistas urbanas conocidas de tiempos medievales se caracterizaban -igual que los primeros mapas- por su carácter simbólico y por la falta de verosimilitud entre la realidad y el elemento dibujado. Entre ellas puede destacarse una vista de la ciudad de Córdoba en un sello del año 1360, que incluye sus principales rasgos -río, puente y mezquita- muy esquematizados (CARO BAROJA, 1958).

Desde mediados del siglo XV y con la llegada del Renacimiento, un fenómeno cultural de marcado carácter urbano, los dibujos de ciudades se aproximarian más a la realidad física. En algunos casos se compusieron múltiples puntos de vista, o perspectivas autónomas, como ocurre en vistas de Roma y Florencia de Massaio (1469) (ARÉVALO RODRÍGUEZ, 2003: 112 y 184). En la Crónica de Nuremberg de Schedel (1493), con 116 vistas de ciudades europeas -no sobre Andalucia-, muchas son más perfiles urbanos que perspectivas, mostrando sus alzados con ausencia total de fugas.
Una temprana vista urbana andaluza, sobre Granada, se pintó al fresco en la Sala de las Batallas del Escorial entre 1584 y 1591 por encargo de Felipe II, en un gran salón de unos 55 metros de largo. Representa la batalla de la Higueruela ganada por Juan II a los nazaries en 1431, y fue copia de una pintura que existió en el Alcázar de Segovia, que debió basarse en apuntes de algún testigo de la contienda. La escena muestra con veracidad lo ocurrido en Granada, según los hechos narrados en las Crónicas de Juan II. Aunque parezca una vista idealizada, las murallas, la Alhambra, Ios Alijares y otros elementos guardan cierta concordancia con la ciudad del momento (GÁMIZ GORDO, 2008: 28-32).

Las representaciones talladas en los tableros de los respaldos de las sillerías de la Catedral de Toledo constituyen la primera gran colección de vistas urbanas andaluzas. Entre 1489 y 1495 alli se plasmaron, con cierta vocación de realismo, escenas de la conquista del Reino de Granada, con 41 poblaciones o plazas fuertes arrebatadas a los nazaries, más siete sin identificar ${ }^{2}$ (MATA CARRIAZO Y ARROQUIA, 1985).

En la lenta evolución de las vistas urbanas hacia una mayor verosimilitud debe destacarse un excepcional óleo anónimo sobre Granada, datable hacia el año 1500, hoy en la colección Mateu (Barcelona). Muestra la Coronación de la Virgen con el Niño e incluye como fondo una vista de Granada desde su vega, con minuciosos detalles que evidencian que no es una vista inventada (ANGULO İ̃NIGUEZ, 1940).

Hasta mediados del siglo XVI pueden recordarse otras vistas esquemáticas, como las publicadas por el cosmógrafo Pedro de Medina en 1548 sobre Sevilla y Granada, dibujadas como núcleos amurallados, ceñidos por un río, y con rasgos genéricos que se repiten en más ciudades andaluzas de la misma obra. Sebastián Münster fue otro autor de libros reeditados a partir de 1540, incluyendo vistas esquematizadas de Sevilla (figura 1), Granada, y la Peña de los Enamorados (GÁMIZ GORD0, 2008: 50-57).

\section{DOS EXCEPCIONALES COLECCIONES DE VISTAS HACIA 1563-67}

El descubrimiento del Nuevo Mundo motivaría en la Europa del siglo XVI una notable curiosidad e interés por conocer otros países y culturas. Muchos monarcas y nobles formaron importantes colecciones de mapas, planos o vistas, y surgió una notoria oferta de libros, atlas y grabados que recopilaban y difundian imágenes esenciales en la historia de la cultura europea. Bajo la influencia de Felipe II, aparecieron en España dos importantísimas colecciones de vistas urbanas dibujadas por Joris Hoefnagel y Anton van den Wyngaerde, hacia 1563-67, con gran interés documental por sus abundantes y precisos detalles.

Frans Hogenberg reelaboró los dibujos de Hoefnagel, y de otros autores, para la monumental obra conocida como Civitates Orbis Terrarum publicada en seis tomos entre 1572 y 1617, con cerca de 

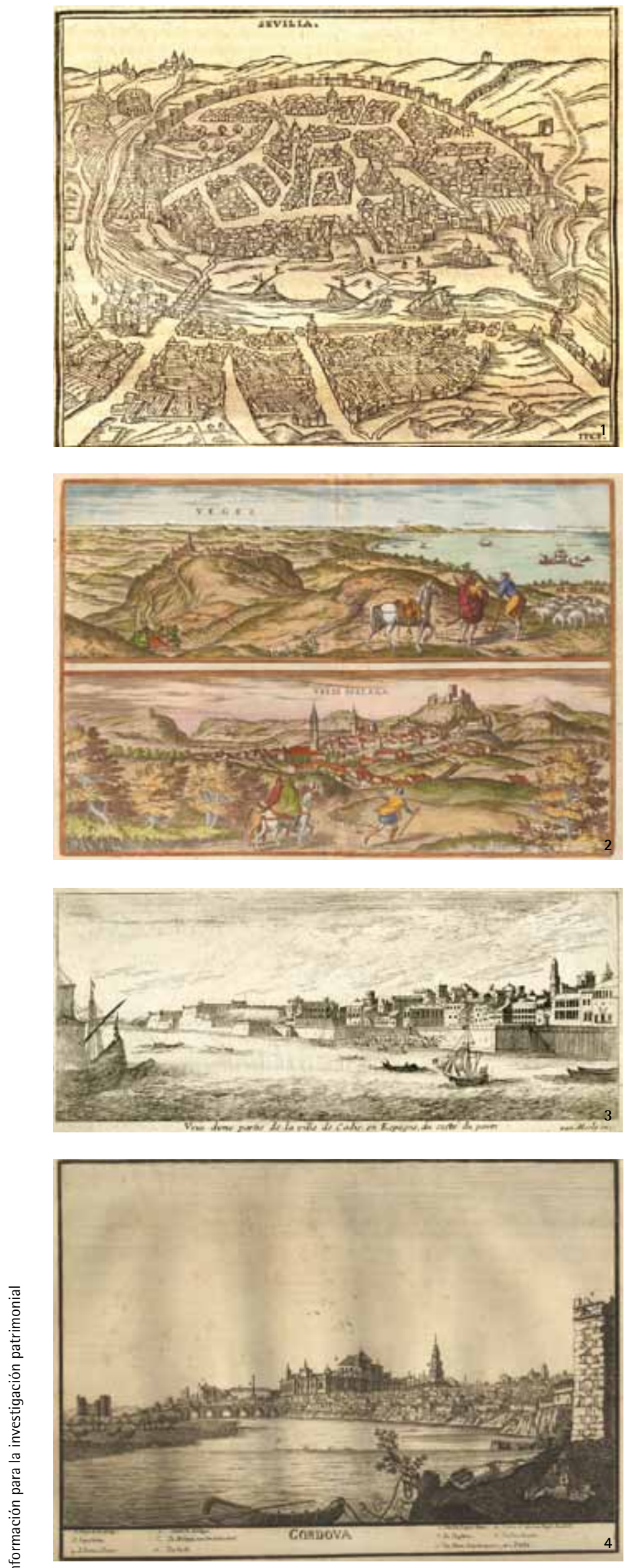

1. Sevilla, h. 1562 (Münster, ed.). Fuente: Colección particular E. Páez

2. Vejer y Vélez Málaga, 1575 (Hoefnagel, dib. / Hogenberg, grab.).

Fuente: Cortesía de Anticuario Ruiz Linares (Granada)

3. Cádiz, h. 1665-68 (Meunier, dib. / van Merle, grab.). Fuente: Colección particular A. Gámiz

4. Córdoba, 1779 (Swinburne, dib. / [Giomignani], grab.). Fuente: Colección particular C. Sánchez
546 vistas urbanas de todo el mundo. La obra incluye 29 láminas con 43 vistas de ciudades españolas, de las que 32 son andalu$\operatorname{zas}^{3}$ (figura 2). Supuso un gran éxito editorial y hacia 1624 habia más de 47 ediciones, en latín, alemán y francés. Además, las vistas fueron plagiadas durante los siglos XVII y XVIII en obras de Meisner, Zeiller, Coronelli o Pieter van der Aa (GÁMIZ GORDO, 2006). El dibujante solía alejarse de las urbes para plasmar su territorio -montañas, ríos, cultivos, etc.- a veces con puntos de vista sobreelevados, reales o imaginarios. El propio Hogenberg decía que las ciudades debian dibujarse mostrando los caminos, calles, edificios y espacios abiertos, y por ello las vistas se retocaban a veces, cediendo parte de su exactitud para ganar facilidad de comprensión.

La otra gran colección de vistas españolas, aún más fiables y precisas, fue dibujada por Anton van den Wyngaerde y ha permanecido inédita hasta finales del siglo XX (KAGAN, 1986; GALERA I MONEGAL, 1998). Constituyen un impresionante conjunto que incluye cerca de 51 vistas de unas 22 poblaciones andaluzas4, conservadas en su mayor parte en la Biblioteca Nacional de Viena y en el Victoria Albert Museum de Londres. Las amplias perspectivas se resolvieron con mucha habilidad, con detalles de una precisión casi notarial. El rigor de los datos gráficos ofrecidos respondía a un claro interés por la verosimilitud, siendo ésta una palabra clave en las vistas urbanas de la segunda mitad del XVI, en las que era frecuente el uso de términos como vero ritratto, vero disegno, vera descrittione, real disegno, fidele ritrato o ad vivum delineata.

\section{VISTAS -MUCHAS SOBRE PLANTAS - DURANTE LOS SIGLOS XVII Y XVIII}

Al igual que ocurrió con las vistas urbanas, los planos de ciudades evolucionaron y se perfeccionaron durante el Renacimiento con precisos recursos gráficos (triangulación, polígonos, etc.). Pero curiosamente, cuando las plantas se resolvian con notable éxito, perderían preponderancia en favor de la más atractiva visualización de las vistas. Entre los siglos XVII y XVIII se abrió una dinámica a la que se ha llamado "el lento divorcio entre la tradición de la vista y la topografía" (SETA, 2001: 50). Y en muchos casos se usaron plantas sin escala para insertar destacados edificios en perspectiva, generándose vistas poco exactas aunque de fácil comprensión.

Además de las populares vistas de la capital andaluza que incluyen el lema "quien no ha visto Sevilla no ha visto maravilla", una de las más importantes vistas urbanas en la Andalucia del XVII fue la Plataforma de Granada dibujada por Ambrosio de Vico y grabada por Heylan hacia 1612-14 (véase la imagen de portada de este monográfico) (GÁMIZ GORDO, 2008: 88-97). Sobre una planta sin escala precisa se detallaron edificios singulares en perspectiva, a veces alterando su orientación para mejorar su visión entre el homogéneo caserio urbano granadino. Aunque las deficiencias al plasmar la compleja topografía son notables, el conjunto es sin duda muy expresivo. 
Entre los siglos XVII y XVIII fueron frecuentes los dibujos de ciudades sobre plantas sin escala, evitando laboriosos procedimientos métricos. La codificación gráfica dependia de los propósitos del dibujante en cada caso, según se deduce al repasar los numerosos dibujos de ciudades españolas conservados en el Archivo de Simancas: San Sebastián (1546), Peníscola (1578), Almonaster la Real (1583), Santiago de Compostela (1595), Melilla (1604), Tarragona (1642), Ciudad Rodrigo (1667)... (ARÉVALO RODRÍGUEZ, 2003: 154-159). En un dibujo anónimo de Cádiz (1609), el viario se esquematiza de forma elemental; y en otro de Almería, de Juan de Oviedo (1621), se omiten calles o caminos ${ }^{5}$.

De gran interés resulta la serie de originales vistas aéreas de Texeira (1634) sobre ciudades portuarias de nuestra península -muchas andaluzas ${ }^{6}$, recientemente publicadas, tras su hallazgo en la $\mathrm{Bi}$ blioteca Nacional de Viena (ATLAS, 2002).

Poco se sabe de Louis Meunier, que dibujó y grabó 17 vistas urbanas originales (h. 1665-68) sobre Granada, Sevilla, Écija y Cádiz (figura 3), más otras pioneras vistas de interiores. Éstas fueron plagiadas, junto a otras vistas del Civitates, en las obras de Pieter van der Berge, con 17 vistas urbanas andaluzas (1700 y 1715); Vicenzo Maria Coronelli con 47 vistas (1706); o Pieter van der $\mathrm{Aa}$, con 44 vistas $(1706,1715 \ldots)$.

En la Biblioteca Laurenziana de Florencia se conserva una magnífica colección de vistas de Pier María Baldi, acompañante de Cosme de Médicis en su viaje por España en 1668-69. Incluye 21 poblaciones andaluzas $^{7}$-más cuatro ventas o cortijos-, siendo muchas de ellas su primera imagen urbana conocida (VIAJE, 2004).

En un dibujo de Andújar de Ximena Jurado (1639) conservado en la Biblioteca Nacional de Madrid (M.S. 1180) sobre la planta de la ciudad aparecen alzados, perspectivas y rótulos descriptivos. Fernández Navarrete dibujó una planta de Granada (h. 1732) incluyendo alzados abatidos, advirtiéndose de su inexactitud en la propia cartela (GÁMIZ GORD0, 2008: 155-166). En el primer plano conocido de Córdoba (1752), sin escala, las iglesias y murallas se representan con esquemáticas perspectivas (GARCIA ORTEGA; GÁMIZ GORDO, 2010). Y algo parecido ocurre en un dibujo más idealizado de la ciudad de Jerez (1768) de José Ángelo Dávila que se encuentra en su Archivo Municipal.

Además son de gran interés una serie de vistas debidas al insigne geógrafo Tomás López, a partir de 1776, con motivo de la elaboración del catastro de Ensenada. Éste recopiló datos y dibujos muy importantes para la historia de muchos pequeños pueblos, tras solicitarles un mapa o plano que a veces englobaba el término municipal. Así, por ejemplo, en el Reino de Granada se contabilizan 167 vistas (GALLEGO ROCA, 1987) que muestran sus municipios de forma intuitiva, con sorprendente expresividad en sus rudimentarios grafismos, ofreciendo datos de gran interés a pesar de sus importantes desproporciones, mezclando a veces plantas, alzados y perspectivas en un mismo dibujo.
A finales del siglo XVIII la Cartografía alcanzaria cierta precisión matemática en los Países Bajos, y también en Francia durante el reinado de Luis XIV, bajo los auspicios de la Academia de las Ciencias. Como temprano ejemplo de las imágenes basadas en nuevos métodos científicos, puede citarse la Carte geometrique de la France de Cassini (1744) que usó redes de triangulaciones para evitar errores dimensionales antes frecuentes.
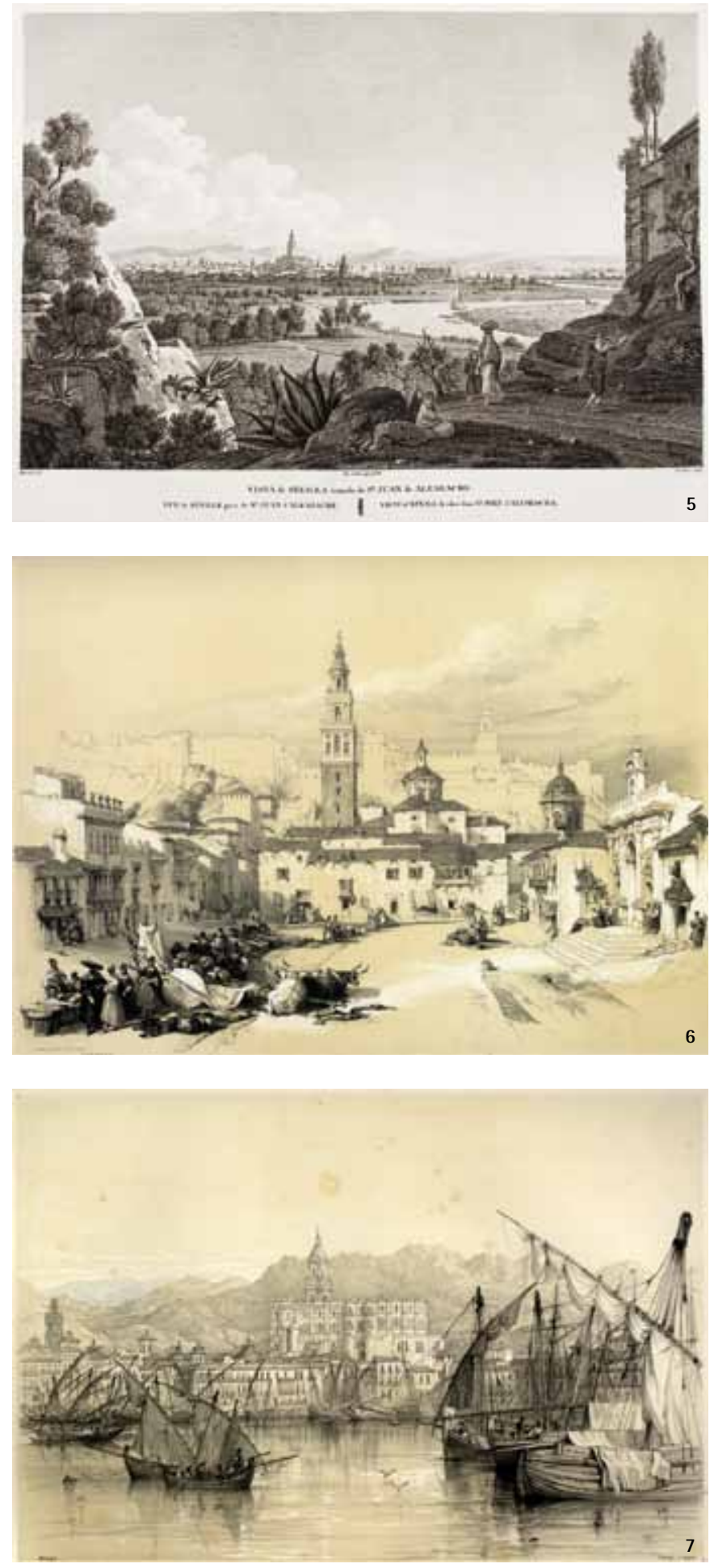

5. Sevilla, 1812 (Laborde, dir. / Vazuelle, dib. / Du Parc, grab.).

Fuente: Colección particular C. Sánchez

6. Carmona, 1838 (Roberts, dib. / Allon, lit.).

Fuente: Cortesía de Grabados Frame (Madrid)

7. Málaga, 1838 (Vivian, dib. / Haghe, lit.)

Fuente: Colección particular C. Sánchez 

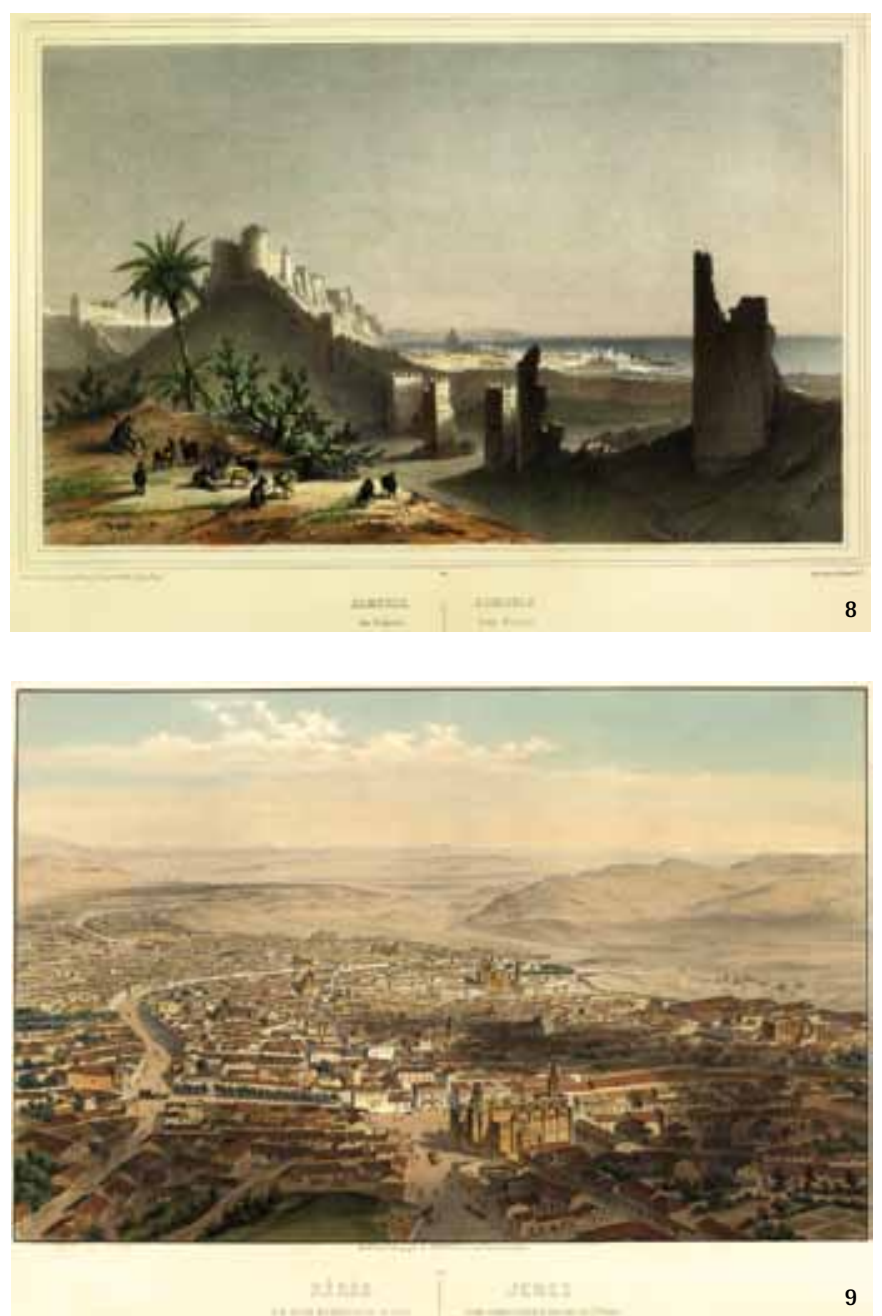

8. Almería, 1844 (Chapuy, dib. / Cuvillier, lit.). Fuente: Cortesía de Laurence Shand (Sevilla)

9. Jerez, h. $1853-55$ (Guesdon, dib. / lit.). Fuente: Colección particular E. Páez

Por entonces surgieron precisos dibujos urbanos, como los levantamientos de la ciudadela de la Alhambra encargados por la Real Academia de San Fernando de Madrid a José de Hermosilla (1766-67), el plano de Olavide en Sevilla (1771), el plano de Dalmau de Granada (1795-96), o el plano de Córdoba de Karwinski (1811). Durante el siglo XIX a éstos les seguirian muchos planos fomentados por las nuevas teorias higienistas, o por proyectos de crecimiento de la ciudad.

Además, a finales del XVIII, aparecieron otras obras, como el Atlante Español de Espinalt (h. 1779-87) con vistas de Córdoba y Jaén grabadas por Palomino; o la publicación de Antonio Ponz (1772-94). Y pasaron por Andalucía viajeros ilustrados, autores de libros con imágenes, como Francis Carter (1772) con 10 vistas de Gibraltar a Málaga, incluyendo Ronda, Marbella, Ardales y Cártama; o Henry Swinburne, con 8 vistas de Granada, Córdoba (figura 4), Málaga y Cádiz (1775-1808).

\section{VISTAS DE CIUDADES Y PAISAJES EN LA 1ª MITAD DEL XIX}

Tras el redescubrimiento de nuestras ciudades por los citados ilustrados, en el XIX se multiplicaron los dibujantes que viajaron recopilando vistas -con notable sensibilidad hacia el paisaje urbano- para editoriales que ofrecian litografías o grabados a las nuevas clases acomodadas europeas. Algunos fueron verdaderos poetas al dibujar nuestras ciudades, creando imágenes muy precisas de una España no industrializada, mostrando paisajes felizmente inalterados, mientras que en Europa la revolución industrial y los nuevos desarrollos urbanos transformaban o incluso borraban las vistas tradicionales de sus ciudades. Se generó así un gran legado gráfico sobre muchos enclaves andaluces -especialmente sobre Granada, Córdoba y Sevilla, más Cádiz y Málaga-, según se constata en la importante bibliografía de libros de viajes de Foulche-Delbosch. Seguidamente se citan algunos autores y colecciones significativas sobre Andalucia hasta mediados deI XIX, cuando el uso generalizado de la fotografía multiplicó los autores y puntos de vista.

A principios del XIX destaca la monumental obra Voyage pittoresque et historique de l'Espagne (4 vol., 1806-1820) de Alexandre de Laborde, que viajó por España con un gran equipo de dibujantes y pintores. El tomo II (1812) incluye 29 vistas urbanas o paisajísticas de Córdoba, Granada, Sevilla (figura 5), Loja, Málaga, Gibraltar, y Cádiz, entre otras, todas de gran calidad. También puede recordarse el libro de Jacob (1811) con 12 vistas más elementales de Sevilla, Alcalá, Jerez, Málaga, Granada, Ronda y Gibraltar. Otra gran obra, la del barón Taylor, publicada hacia 1827, incluye bastantes vistas -con calidad gráfica inferior a Laborde- sobre Gibraltar, Algeciras, Ronda, Antequera, Granada, Córdoba, Sevilla, Cádiz y el Puerto de Santa María.

En la década de 1830-40 pasaron por Andalucia excepcionales dibujantes y paisajistas, autores de precisas visiones que a veces ilustraron obras literarias con cierto carácter romántico u orientalista, consideradas por algunos como el origen o la invención de nuestras ciudades como paisajes turisticos. Uno de los más importantes fue sin duda Richard Ford, bastante conocido por sus escritos, que hacia 1831-33 realizó multitud de vistas de ciudades y paisajes con inéditos puntos de vista (SEVILLA, 2007). David Roberts fue otro singular paisajista y escenógrafo, cuyos grabados y litografias sobre Andalucia (1835-38) gozan aún hoy de gran popularidad (figura 6), al igual que sus incontables dibujos originales en museos de todo el mundo (GÁMIZ GORDO, 2010). No deben olvidarse las exquisitas litografías de Lewis con el paisaje de la Alhambra (1833-35), ni las 11 vistas de la ciudad granadina (más 2 cordobesas) de Girault de Prangey (1832-37), o las 22 preciosas vistas urbanas de George Vivian (1834-39) sobre Córdoba, Granada, Sevilla, Málaga (figura 7), Cádiz, Gibraltar, Vélez Málaga y Almuñécar.

En la década de 1840 sobresalen las más de 30 vistas paisajísticas de Nicolás Chapuy (h. 1842-44) sobre Almeria (figura 8), Málaga, Vélez Málaga, Alhama, Granada Gibraltar, Cádiz, Jerez, Puerto de Santa Maria, Sevilla, Carmona, Écija y Córdoba; todas ellas muy precisas, pues se basarian en daguerrotipos, al igual que la gran colección de vistas de Francisco Javier Parcerisa (1850-56). 
Y finalmente se destacan 12 vistas andaluzas de gran precisión, dibujadas por Alfred Guesdon (h. 1853-55) sobre Gibraltar, Algeciras, Cádiz, Jerez (figura 9), Córdoba, Sevilla, Granada y Málaga. Se realizaron con novedosos puntos de vista aéreos, mediante primitivas fotos tomadas desde un globo aerostático, ofreciendo bellas visiones de paisajes urbanos labrados durante siglos y que después se transformaron con la llegada del llamado "progreso" (GÁMIZ GORD0, 2004).

\section{Notas}

1 Quiero expresar mi especial gratitud a Carlos Sánchez y a Eduardo Páez por facilitar vistas de sus colecciones particulares y una valiosa información sobre las mismas; al igual que a Fernando Carnicero (Anticuario Ruiz Linares, Granada), Jaime Armero (Grabados Frame, Madrid) y Laurence Shand (Mapas y Grabados, Sevilla).

${ }^{2}$ Alhama, Lucena, Alora, Setenil, Coin, Cartaza, Ronda, Marbella, Loja, Íllora, Moclin, Montefrio, Vélez Málaga, Comares, Santa Fe, Málaga, Vera, Mojácar, Nijar, Vélez Blanco, Huercal, Cabrera, Cantoria, Huéscar, Baza, Guadix, Serón, Purchena, Gor, Almeria, Almuñécar, Salobreña, Almería, Rion, Zújar, Cambriles, Castril, Castel Ferro, Nieles, Otura, Padul, Granada.

${ }^{3}$ Alcantarilla, Alhambra y Granada, Antequera, Archidona, Ardales, Bornos, Cádiz, Cártama, Conil, Córdoba, Écija, Jerez de la Frontera, Las Cabezas, La Peña de los Enamorados, Loja, Lebrija, Málaga, Marchena, Osuna, San Juan de Aznalfarache. ${ }^{4}$ Málaga, Peñón de Vélez de la Gomera, Córdoba, Úbeda-Baeza, Jaén, Granada, Alhama de Granada, Antequera, la costa de África desde España (y Melilla), Ojén, Gibraltar, Tarifa, Zahara de los Atunes, Cádiz, Puerto de Santa María, Jerez de la Frontera, Sanlúcar de Barrameda, Sevilla, Itálica, Carmona, Écija.

${ }^{5}$ Vista de la ciudad de Cádiz, anónima, 1609 (M. P. y D. XIX-124. Estado, leg. 216). Planta de la ciudad de Almeria por Juan de Oviedo, 1621 (Archivo General Simancas M. P. y D. XXIX-22. G. A. leg. 872).

${ }^{6}$ Ayamonte, Huelva, Cádiz-Sanlúcar, Gibraltar-Algeciras, Ceuta, Tánger, Estepona, Marbella, Fuengirola, Málaga, Torre del Mar-Vélez Málaga, Castell de Ferro, Almería. ${ }^{7}$ Linares, Andújar, El Carpio, Alcolea, Córdoba, Castro del Río, Alcalá la Real, Pinos Puente, Granada, Santa Fe, Loja, Rute, Lucena, Montilla, Écija, Fuentes de Andalucia, Carmona, Sevilla, Castiblanco de los Arroyos, Santa Olalla de Cala.

\section{Bibliografía}

AA, P. (VAN DER) (ed.) (1707) Beschryving van Spanjen en Portugal. Leiden: Pieter van der Aa., 1707

ANGULO íNIGGEZ, D. (1940) La ciudad de Granada vista por un pintor flamenco hacia 1500. Al-Andalus, t. V, pp. 468-472

ÁlVAREZ DE COLMENAR, J. (ed.) (1715) Les Delices de L'Espagne \& du Portugal, (6 vol.) Leiden: Pierre van der $\mathrm{Aa}, 1707$

ARÉVALO RODRÍGUEZ, F. (2003) La representación de la ciudad en el Renacimiento. Levantamiento urbano y territorial. Barcelona: Fundación Caja de Arquitectos, 2003

ATLAS del Rey Planeta. La descripción de España y de las costas y puertos de sus reinos de Pedro Texeira (1634). Hondarribia: Nerea, 2002

BERGE, P. (VAN DER) (1700) Theatrum hispaniae exhibens regni urbes, villas ac viridaria magis illustria. Tot Amsterdam: Pieter Vanden Berge, 1700 BRAUN, G; HOGENBERG, F. (ed.) (1572-1617) Civitates Orbis Terrarum (6 vol.) Colonia y Amberes, 1572-1617

CABRA LOREDO, M. D.; SANTIAGO PÁEZ, E. M. (ed.) (1988) Iconografía de Sevilla 1400-1650. Madrid: El Viso, 1988

CALVO SERRALLER, F.; CARRETE PARRONDO, J.; LLEÓ, V. et ál. (1991) Iconografía de Sevilla. 1790-1868. Madrid: Ediciones EI Viso, 1991 CARO BAROJA, J. (1958) La ciudad de Córdoba desde la orilla izquierda del Guadalquivir, según un sello del siglo XIV. Al-Andalus, XXIII, 1, 1958, pp.197-ss. CARTER, F. (1777) A Journey from Gibraltar to Malaga. London: [s.n.], 1777 CATÁLOGO de la colección de estampas de la Fundación Focus. Sevilla: Fundación Fondo de Cultura de Sevilla, 1996

CHAPUY, N. (h.1844) L'Espagne. Vues des principales Villes de ce Royaume

Dessinées d'après nature par Chapuy. Bulla: Paris, h. 1844
CORONELLI, V. M. (1706) Teatro della guerra, Gran Bretagna, Spagna, Portogallo. vol. II, Venecia, 1706

COSANO MOYANO, F. (1999) Iconografía de Córdoba. Córdoba: CajaSur, 1999 FOULCHÉ-DELBOSC, R. ([1880] 1991) Bibliographie des voyages en Espagne et en Portugal. [H. Welter, Paris]. Madrid: Julio Ollero Editor, 1991

GALERA I MONEGAL, M. (1998) Antoon van den Wijngaerde, pintor de ciudades y de hechos de armas en la Europa del Quinientos. Barcelona: Fundación Carlos de Amberes / Institut Cartogràfic de Catalunya, 1998

GALLEGO ROCA, F. J. (1987) Morfología urbana de las poblaciones del reino de Granada a través del Catastro del Marqués de la Ensenada. Granada: Diputación, 1987

GÁMIZ GORDO, A. (2004) Paisajes urbanos vistos desde globo: dibujos de Guesdon sobre fotos de Clifford hacia 1853-55. Revista EGA, n. ${ }^{9}$, 2004, pp. 110-117 GÁMIZ GORDO, A. (2006) Cinco grabados de Vejer. Vejer de la Frontera (Cádiz): Sociedad de Amigos del Pais, 2006

GÁMIZ GORDO, A. (2008) Alhambra. Imágenes de ciudad y paisaje (hasta 1800). Granada: Fundación el Legado Andalusi / Patronato de la Alhambra y Generalife, 2008

GÁMIZ GORDO, A. (2010) Las vistas de España del viajero David Roberts, pintor de paisajes y arquitecturas, hacia 1833. Revista $E G A, n .{ }^{\circ} 15,2010$, pp. 54-65

GARCÍA ORTEGA, A. J.; GÁMIZ GORDO, A. (2010) La ciudad de Córdoba en su primer plano: un dibujo esquemático de 1752. Archivo Español de Arte, v. 83, n. ${ }^{\circ}$ 329, 2010, pp. 23-40

GIRAULT DE PRANGEY, P. (1837) Monuments arabes et moresques de Cordoue, Seville et Grenada. Paris: Veith and Hauser, 1837

GUESDON, A. (h.1853) L'Espagne a vol d'odiseau. Paris: Hauser y Delarue, h. 185355

JACOB, W. (1811) Travels in the south of Spain. Letters written A.D. 1809 and 1810. Londres: J. Johnson and Co.\&t W. Miller, 1811

KAGAN, R. L. (dir.) (1986) Ciudades del Siglo de Oro. Las vistas españolas de Anton van den Wyngaerde. Madrid: El Viso, 1986

LABORDE, A. (1812) Voyage pittoresque et historique de l'Espagne (t. II). Paris: Pierre Didot l'Aine, 1812

LEWIS, J. F. (1835) Sketches and drawings of the Alhambra made during a residence in Granada in the years 1833-34. London: C. Hullmandells, s.a., 1835 MATA CARRIAZO Y ARROQUIA, J. (DE) (1985) Los relieves de la Guerra de Granada en la Sillería del Coro de la Catedral de Toledo. Granada: Universidad, 1985 MEDINA, P. (DE) (1548) Libro de las Grandezas y Cosas Memorables de España. Sevilla: impresor Doménico de Robertis, 1548

MEISNER, D. (h.1626) Thesaurus sapientiae civilis, sive vitae humanae ac virtutum et vitiorum Theatrum. Francofurti: [s.n.], h. 1626

MEUNIER, L. (1665-1668) Diuersas vistas de Las casas y Jardines de placer del Rei despana. Paris: se vend Chez N. Bonnart, ruë St. lacques a l'aigle auec priuil., (16651668)

MÜNSTER, S. (h. 1542-1562) Cosmographia universalis [edición de 1562]. Basilea PARCERISA, F. J. (1839-72) Recuerdos y bellezas de España (12 vol.). Madrid: imprenta de D. José María Repullés, 1839

ROBERTS, D. (1837) Picturesque sketches in Spain taken during the years 18321833. London: Hocgson and Graves, 1837

ROBERTS, D.; ROSCOE, T. (1835-38) The tourist in Spain (4 vol.). Londres: R. Jennings, 1835

SERRERA, J. M.; OLIVER, A. (1989) Iconografia de Sevilla. 1650-1790. Madrid: Ediciones el Viso, 1989

SETA, C. (DE) (2001) Introduzione. En SETA, C. DE; STROFFOLINO D. L'Europa moderna. Cartografia urbana e vedutismo. Milán: Electa, 2001, pp. 11-56 La SEVILLA de Richard Ford, 1830-1833. Sevilla: Fundación El Monte, 2007 SWINBURNE, H. (1779) Travels through Spain in the years 1775 and 1776. London: P. Elmsly, 1779

TAYLOR, I. S. J. (1826-60) Voyage pittoresque en Espagne, en Portugal et sur la côte d'Afrique, de Tanger a Tétuan. Paris: Librairie de Gide Fils, 1826, t. III

EI VIAJE a Compostela de Cosme III de Médicis. Santiago de Compostela: Servicio de Publicaciones del Xacobeo, Xunta de Galicia, 2004

VIVIAN, G. (1838) Spanish Scenery. Londres: P. \& D. Colnaghi, 1838 ZEILLER, M. (1656) Hispaniae et Lusitaniae itinerarium : nova et accurata descriptione, iconibusq novis et elegantibus loca earundem proecipua illustrans. Amstelodami [Amsterdam]: apud Aegidium lanssonium Valckenier, 1656 